\title{
Proses Employer Branding PT. Mercedes-Benz Indonesia untuk Meningkatkan Eksistensi Perusahaan
}

\author{
${ }^{1}$ Tasya Vicky Ryana, ${ }^{2}$ Hanny Hafiar, ${ }^{3}$ Syauqy Lukman \\ Program Studi Hubungan Masyarakat, Fakultas Ilmu Komunikasi, Universitas Padjadjaran, Bandung \\ E-mail: 'tasyaryana@hotmail.com, ${ }^{2}$ hannyhafiar@gmail.com, ${ }^{3}$ syauqy.lukman@unpad.ac.id
}

\begin{abstract}
Abstrak: Citra merupakan dampak persepsi publik atas komunikasi pemasaran yang dilakukan suatu perusahaan. Salah satu perusahaan otomotifmulti-nasional terbesar di dunia, Mercedes-Benz pun masih menyadari pentingnya membangun citra untuk perusahaannya dengan upaya branding. Melalui Indonesia Most Admired Companies (IMACO) Award oleh Warta Ekonomi Intelligence Unit (WEIU), perusahaan di Indonesia bersaing untuk menjadi perusahaan yang unggul dibandingkan dengan kompetitor. PT. Mercedes-Benz Indonesia yang dikenal sudah memiliki product knowledge baik dikalangan publiknya dirasa belum maksimal membangun company knowledge karena belum mendapatkan peringkat dalam IMACO Award. Suatu urgensi untuk membedakan perusahaan dengan perusahaan lainnya sebagai employer mendorong perusahaan untuk melakukan strategi Employer Branding. Karena itu penulis tertarik untuk melakukan penelitian lebih dalam mengenai proses employer branding yang dilakukan oleh PT. Mercedes-Benz Indonesia untuk mencapai predikat Most Admired Company. Penelitian ini merupakan penelitian deskriptif dengan jenis data kualitatif. Hasil dari penelitian ini mengungkapkan bahwa; 1) pembentukan employer value proposition diawali dengan mempelajari harapan dan tujuan perusahaan yang diterapkan menjadi suatu nilai dan budaya perusahaan, 2) tahap external marketing evp dilakukan dengan menargetkan publik umum dan prospective candidate dengan tujuan untuk menanamkan citra baik perusahaan di pikiran calon karyawan 3) tahap internal marketing evp dijalankan dengan program pengembangan dan keterlibatan karyawan untuk meningkatkan kualitas dan kemampuannya.
\end{abstract}

Kata kunci: pemberi kerja, pekerja, citra, proposisi nilai perusahaan.

\begin{abstract}
Image is a public perception that's caused by marketing communication of the organization. One of the largest automotive company in the world, Mercedes-Benz is still aware of the importance of building image with branding. Through Indonesia Most Admired Companies (IMACO) Award by the Warta Ekonomi Intelligence Unit (WEIU), companies in Indonesia compete to be superior companies compared to competitors. PT. Mercedes-Benz Indonesia, which is known to have good product knowledge among the public, is considered to have low company's knowledge because it has not been ranked in the IMACO Award. The urgency to differentiate company with other companies as the employer encourages companies to carry out the employer branding strategy. Therefore, the author is interested in conducting further research on employer branding processes carried out by PT. Mercedes-Benz Indonesia to reach the title of the Most Admired Company. This research is a descriptive study with a qualitative data. The results of this study reveal that; 1) the formation of the employer value proposition begins with the expectations and objectives of the company that are applied in accordance with the values and corporate culture, 2) the external marketing evp is carried out by involving the general public and prospective candidates to build good image in their minds. 3) the internal marketing evp is run with employee development and engagement programs to improve their quality and capabilities.
\end{abstract}

Keywords: employer brand, employer, employee, employer value proposition, image.

DOI: https://doi.org/10.29313/mediator.v12i2.4921 


\section{PENDAHULUAN}

Konsep citra dalam dunia bisnis telah berkembang dan menjadi perhatian para pemasar. Citra adalah tujuan, sekaligus merupakan prestasi yang hendak dicapai oleh setiap perusahaan. Citra dapat ditumbuhkan dari usaha memahami publik, mendapatkan perhatian publik, dan mendapatkan kepercayaan penuh dari publik, usaha ini dikenal dengan branding. Permasalahannya adalah bagaimana mengkomunikasikan usaha branding kepada publik, untuk menumbuhkan citra yang baik. Kegiatan branding saat ini tidak hanya dibutuhkan oleh perusahaan-perusahaan kecil yang baru dibangun, namun perusahaan besar yang sudah memiliki brand yang baik pun, masih tetap merasakan pentingnya usaha branding.

Sebagai salah satu perusahaan otomotif multi-nasional terbesar di dunia, eksistensi Mercedes-Benz sudah tidak lagi diragukan oleh publik. Namun, PT Mercedes-Benz Indonesia masih menyadari pentingnya branding untuk perusahaannya. Pambayun Prayoga selaku HR Marketing \& Industrial Relation PT. Mercedes-Benz Indonesia mengatakan bahwa perusahaan PT Mercedes-Benz sendiri belum maksimal dalam melakukan branding perusahaan karena terlalu fokus dalam branding dan pemasaran produk dan jasa MercedesBenz. Hal ini dilihat dari pengetahuan publik yang tidak mengerti tentang keberadaan perusahaan PT MercedesBenz di Indonesia dan tingkat perputaran karyawan yang relatif rendah.

Informasi tentang perusahaan PT. Mercedes-Benz Indonesia di kalangan public eksternal dapat dikatakan tinggi jika dilihat dari produk dan jasa yang ditawarkan. Namun, informasi tentang perusahaan PT. Mercedes-Benz Indonesia sebagai suatu perusahaan yang utuh dan sebagai pemberi kerja dapat dikatakan relatif rendah jika disandingkan dengan informasi atau pengetahuan tentang jasa dan produk di kalangan publik. Suatu desakan untuk membedakan perusahaan dengan perusahaan lainnya sebagai employer dan sekaligus menempati posisi sebagai perusahaan yang terlihat menarik di kalangan publik, mendorong perusahaan untuk melakukan strategi Employer Branding.

Corporate branding mengacu kepada bisnis atau perusahaan secara utuh (Smykal, 2016). Sedangkan employer branding didefinisikan sebagai pengkomunikasian kepada karyawan yang sedang dipekerjakan saat ini dan calon karyawan (Lloyd, 2002). Banyak perusahaan yang berkompetisi untuk mendapatkan kandidat terbaik yang berpotensi, karena itu menjadi employer yang ideal dilihat sangat penting bagi perusahaan. Jadi employer branding diperluas sebagai strategiyangmenghadap ke eksternal, mempromosikan keuntungan dari bekerja di perusahaan tersebut sebagai cara untuk merekrut kandidat, atau untuk meningkatkan employer image yang merupakan pendukung dari corporate brand. Setiap perusahaan pasti ingin menjadi perusahaan idaman, tetapi bukanlah hal yang mudah untuk mencapai predikat tersebut. Menjadi perusahaan yang diidamkan oleh para karyawan dan pencari kerja merupakan hal yang sangat penting bagi keberlangsungan perusahaan.

Bagi perusahaan, menyandang predikat perusahaan idaman memberikan keunggulan dalam berkompetisi. Dengan menjadi perusahaan idaman para karyawan menunjukkan bahwa terdapat kepuasan kerja bagi karyawan dalam perusahaan tersebut. Kepuasan kerja ini yang mendorong peningkatan dalam perusahaan tersebut. Selain itu, perusahaan yang diidamkan oleh para pencari kerja juga membuat perusahaan tersebut dapat memilih kandidat karyawan dengan kemampuan terbaik di 


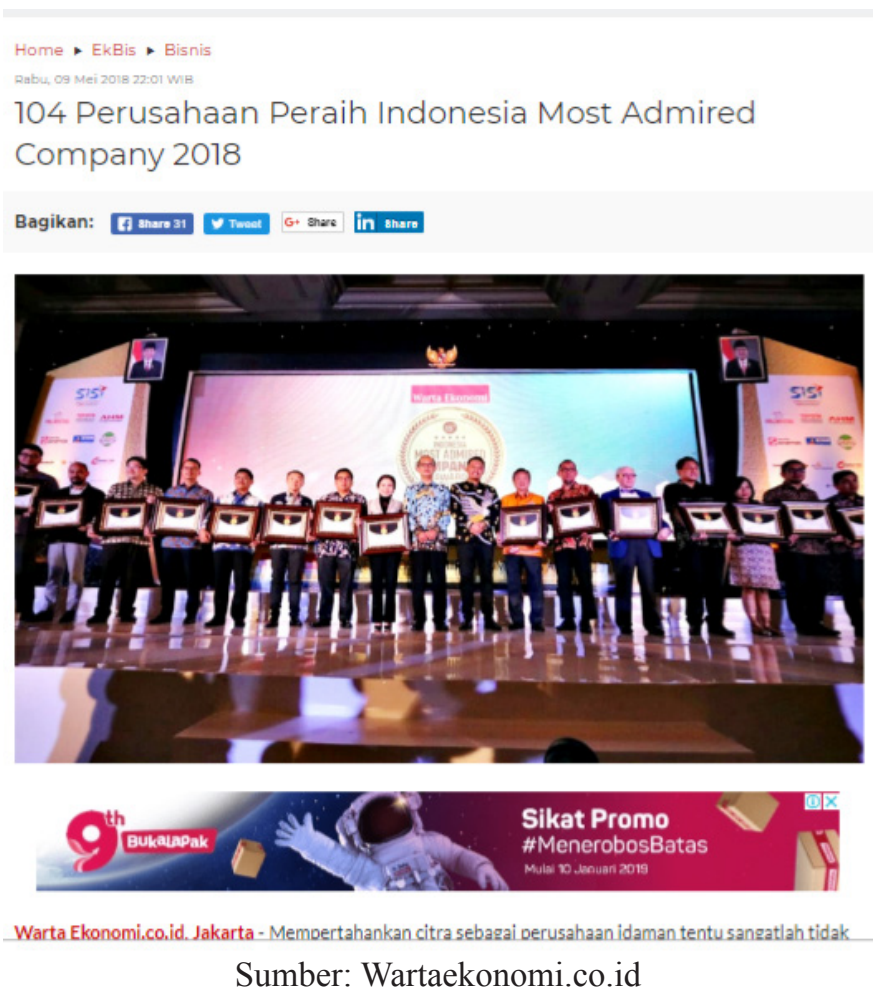

GAMBAR 1. Berita Online Indonesia Most Admired Company 2018

Pada Laman Wartaekonomi.co.id

antara kandidat lainnya.

Melalui Indonesia Most Admired Companies (IMACO) Award yang dibuat oleh Warta Ekonomi Intelligence Unit (WEIU), perusahaan-perusahaan di Indonesia bersaing dalam mendapatkan predikat tersebut sebagai bukti bahwa perusahaannya unggul dibandingkan dengan perusahaan lain di bidang yang sama.

PT. Mercedes-Benz Indonesia yang dikenalsudahmemilikiproductknowledge sangat baik di kalangan publiknya, dirasa belum maksimal membangun company knowledge karena belum pernah mendapatkan peringkat dalam IMACO Award. Segala aktivitas komunikasi yang dijalankan baik internal dan eksternal oleh organisasi harus berjalan secara terintegrasi, interaktif, interdependensi dan sinergetik dan dilakukan untuk mendukung organisasi sebagai sebuah brand. Tujuan utama employer branding yang dilakukan oleh PT. Mercedes-Benz Indonesia adalah untuk meningkatkan eksistensi perusahaan di benak publik dan membangun corporate knowledge yang lebih kuat dan kemudian berpengaruh kepada mendukung corporate brand yang lebih kuat pula (Prayoga, 2019). Namun, upaya untuk memasarkan nilainilai perusahaan yang telah ada, dirasa belum maksimal.

Dalam proses employer branding yang dilakukan oleh PT. MercedesBenz Indonesia, tahap pemasaran atau marketing dari nilai-nilai perusahaan belum dijalankan secara optimal (Prayoga, 2019). Pemasaran keluar perusahaan yang disebut juga sebagai external marketing dari employer branding merupakan salah satu tahapan proses employer branding dalam konsep yang dirancang oleh Backhaus dan Tikoo, yang terdiri dari pembentukan employer value proposition, external marketing, dan internal marketing. Untuk menganalisis lebih lanjut mengenai upaya-upaya penerapan Employer Branding yang dilakukan oleh PT. Mercedes-Benz Indonesia, 
penulis tertarik untuk mengambil topik mengenai tahapan Employer Branding yang dilakukan oleh PT. MercedesBenz Indonesia dalam membangun citra perusahaan sebagai tempat bekerja yang ideal dan menjadikan perusahaan sebagai Most Admired Company (Backhaus \& Tikoo, 2004).

Berdasarkan uraian di atas, penulis tertarik untuk melakukan penelitian lebih dalammengenaiprosesemployerbranding yang dilakukan oleh PT. Mercedes-Benz Indonesia untuk mencapai predikat Most Admired Company.

\section{METODE}

Metode penelitian yang digunakan adalah metode penelitian deskriptif kualitatif. Metode deskriptif dengan data yang disajikan secara kualitatif, yakni sebuah desain yang memberi kemudahan bagi peneliti untuk merekam, memantau dan mengikuti proses suatu peristiwa atau kegiatan sebuah organisasi sebagaimana adanya dalam suatu kurun waktu tertentu dan selanjutnya diinterpretasikan untuk menjawab masalah penelitian.

Dalam penelitian ini, subjek penelitian merupakan narasumber yang mengalami langsung situasi atau kejadian yang berkaitan dengan topik penelitian. Narasumber yang bertindak sebagai informan juga harus dapat menggambarkan kembali fenomena yang telah dan sedang dialami.

Subjek dalam penelitian ini adalah tiga orang employer PT. Mercedes-Benz Indonesia sebagai pihak yang merancang dan turut berperan langsung dalam proses employer branding PT. Mercedes-Benz Indonesia, yaitu Pambayun Prayoga selaku HR Marketing \& Industrial Relation, Niena S. Khotimah selaku HR Planning \& Compliance, dan Rachman H. Harahap selaku HR Talent Acquisition. Serta tiga orang karyawan PT. MercedesBenz Indonesia yang mengalami atau menjadi publik dalam proses employer branding PT. Mercedes-Benz Indonesia, yaitu Grahan Ardiwianto, Argita Maya Fauzi, dan Serawanti Deliana sebagai karyawan PT. Mercedes-Benz Indonesia. Objek dalam penelitian ini adalah proses employer branding yang dilakukan oleh PT. Mercedes-Benz Indonesia. Di dalam penelitian ini, proses employer branding yang akan dibahas adalah proses employer branding yang melalui tiga tahap, yaitu Employer Value Proposition, External Marketing, dan Internal Marketing yang dikonsepkan oleh Backhaus dan Tikoo (2004).

Penelitian ini dilakukan pada Januari sampai Mei 2019, di PT. Mercedes-Benz Indonesia yang berlokasi di Jalan Raya Mercedez Benz, Wanaherang, Gunung Putri, Cicadas, Gn. Putri, Bogor, Jawa Barat 16965. Dalam penelitian ini, data yang diperoleh peneliti didasarkan pada beberapa sumber bukti yang berlainan yaitu wawancara mendalam, observasi dan dokumen.

\section{HASIL DAN PEMBAHASAN}

Employer branding adalah suatu fenomena pada jalannya perusahaan namun masih dianggap sebagai konsep yang samar. Aktivitas employer branding menempati posisi yang penting pada strategi perusahaan dan umumnya menjadi tanggung jawab dari departemen Human Resources dan Corporate Communication. Departemen ini memiliki tanggung jawab besar untuk mengembangkan dan mempertahankan image perusahaan baik sebagai perusahaan pemberi kerja ataupun perusahaan secara keseluruhan. Konsep employer branding mengadaptasi konsep marketing dan public relations jika dilihat dari penerapan aktivitasnya yang bertujuan untuk menanamkan suatu pemikiran atau ide pada pikiran publiknya, dan menghasilkan suatu pandangan atau citra dari publik terhadap perusahaan tersebut.

Prinsip marketing ini berhubungan 
dengan tahapan internal marketing untuk mengingatkan, menanamkan, dan mengikat karyawan yang telah ada kepada nilai-nilai dan tujuan perusahaan yang sudah ditentukanoleh perusahaan tersebut. Prinsip tersebut juga berhubungan dengan tahap external marketing untuk menarik kandidat atau prospective employees (Backhaus \& Tikoo, 2004). Dalam konteks fenomena ini, 'branding' menawarkan perbedaan karakteristik perusahaan sebagai perusahaan pemberi kerja dengan kompetitornya.

Dalam proses employer branding, tahap pertama adalah mengembangkan identitas perusahaan yang dinamakan employer value proposition, bertujuan untuk menjadi representasi dari apa yang dijanjikan oleh perusahaan kepada karyawannya, value proposition ini menjabarkan pesan utama yang ingin disampaikan oleh brand perusahaan. Value perusahaan yang ditawarkan atau dipasarkan terdiri dari budaya perusahaan, gaya manajemen, kualitas dari karyawan saat ini, citra ketenagakerjaan saat ini, dan pandangan terhadap produk yang dihasilkan perusahaan tersebut (Backhaus \& Tikoo, 2004).

PT. Mercedes-Benz Indonesia merumuskan employer value proposition dari perusahaan dengan menonjolkan ciri khas perusahaan yang ingin ditunjukkan kepada publik, serta pesan-pesan perusahaan yang ingin disampaikan kepada publiknya dengan tujuan untuk menjadikan EVP tersebut sebagai representasi perusahaan tentang apa yang ingin ditawarkan ke pihak internal dan eksternal perusahaan. PT. MercedesBenz Indonesia telah membentuk budaya perusahaan dengan dilandaskan pemikiran panjang dan makna mendalam agar dapat dimanfaatkan sebagai landasan dalam setiap perilaku yang diterapkan pada pekerjaan sehari-hari. Budaya ini juga dianggap sebagai value atau nilai perusahaan yang pada waktu bersamaan ditentukan menjadi suatu tujuan perusahaan yang dalam perusahaan ini adalah mengajak seluruh karyawan untuk bersama-sama memikirkan arah berjalannya perusahaan. PT. MercedesBenz Indoneia memiliki $A B C$, yang berarti Attitude Behavior Change. Nilai di dalamnya adalah PRIDE; Passion, Respect, Integrity, Discipline and Excellence. Nilai ini dirancang oleh DAIMLER dan diterapkan ke MercedesBenz Indonesia (Prayoga, 2019).

Visi misi perusahaan yang telah dibentuk dan diterapkan dalam perusahaan diharapkan dicerminkan di tiap tingkah laku seluruh karyawan termasuk pada setiap pekerjaan dan tanggung jawab yang dikerjakan. Budaya perusahaan yang sudah terinternalisasi dalam tingkah laku karyawan akan menjadi ciri khas perusahaan yang membedakan dirinya dari perusahaan sejenis atau kompetitor.

Budaya perusahaan yang dirancang oleh manajerial perusahaan tersebut bukan semata-mata hanya rangkaian kata yang tidak berlandaskan sebab. Namun dirancang dan diterapkan dengan harapan perusahaan bahwa budaya tersebut akan menjadi suatu jiwa bagi seluruh karyawan pada perusahaan untuk mencapai tujuan utama secara bersama-sama. Seperti yang dikatakan oleh Backhauss and Tikoo (2004: 508),

Organizational culture research provides further support for the assertion that employer brand messages can convey important pre-employment information. Organization culture is important to applicants in making a job choice. Their beliefs about the firm's culture affect the validity of self-selection decisions and affect their post-entry performance. Thus, we argue that employer branding messages should communicate accurate information about the culture."

Selain visi-misi yang dimiliki 
Tasya Vicky Ryana, dkk. Proses Employer Branding PT. Mercedes-Benz Indonesia...

oleh perusahaan, gaya manajemen yang diterapkan oleh perusahaan juga dapat dirasakan menjadi nilai-nilai perusahaan yang menjadi ciri khas perusahaan tersebut. Di saat budaya perusahaan disebut sebagai nilai-nilai atau keyakinan yang menghasilkan pola perilaku tertentu dari keseluruhan karyawan atau sumber daya manusia yang ada dalam suatu perusahaan, maka gaya manajemen (management style) lebih bersifat kepada bagaimana cara atau style dari para pemimpin memperlihatkan budaya yang berlaku di perusahaan tersebut.

PT. Mercedes-Benz Indonesia mengadaptasi gaya manajemen perusahaan DAIMLER yang merupakan mother company dari Mercedes-Benz. Gaya manajemen yang umumnya digunakan oleh perusahaan multinational Europe ini memengaruhi gaya bekerja dan hubungan seluruh karyawan dalam perusahaan. Gaya bekerja karyawan yang dipengaruhi oleh gaya manajemen, biasanya dirasakan pada seluruh aktivitas yang dilakukan setiap hari oleh karyawan, dan hal itu mempengaruhi tingkat produktivitas dari sebuah perusahaan.

Gaya manajemen perusahaan Jerman memberikan dorongan etos kerja yang tinggi kepada seluruh karyawan PT. Mercedes-Benz Indonesia dengan menghormati waktu dan tanggung jawab satu sama lain dalam seluruh pekerjaan yang dilakukan. Budaya perusahaan dan gaya manajemen yang baik pada perusahaan mendorong karyawannya untuk bekerja dengan maksimal dan menumbuhkan rasa loyalitas terhadap perusahaannya karena merasa nyaman bekerja di perusahaan tersebut. Hal ini menimbulkan kecenderungan rendahnya perputarankaryawan (employeeturnover), yang berarti kebanyakan karyawan dalam perusahaan tersebut merupakan karyawan yang sudah menghabiskan banyak waktu melakukan pekerjaan yang sama. Perputaran karyawan yang cenderung rendah pada PT. MercedesBenz Indonesia berarti menunjukkan bahwa mayoritas pekerjaan dan tanggung jawab dikerjakan oleh karyawan yang sama selama bertahun-tahun. Dari sisi perusahaan, tingkat turnover bisa menjadi hal positif maupun negatif yang mempengaruhi kinerja perusahaan.

Dari pernyataan yang didapatkan oleh peneliti di lapangan, tingkat employee turnover yang rendah pada PT. Mercedes-Benz Indonesia tidak mengganggu jalannya perusahaan karena pihak manajerial menganggap hal itu berarti perusahaan sudah memberikan lingkungan kerja yang nyaman dan mensejahterakan karyawannya sehingga mereka merasa nyaman berada di suatu posisi atau pekerjaan yang sama dalam waktu yang lama.

Kualitas karyawan yang telah dimiliki oleh perusahaan juga menjadi suatu ciri khas perusahaan yang ingin dipasarkan oleh perusahaan (EVP). Pihak manajerial PT. Mercedes-Benz Indonesia mengatakan bahwa kualitas karyawan yang sudah dimiliki perusahaan dianggap sudah memenuhi standard yang ada.

Kualitas karyawan yang telah dimiliki dinilai sudah sangat baik karena sudah memberikan apa yang perusahaan minta dan memenuhi apa yang perusahaan butuhkan. Kualitas karyawan yang menjadi salah satu ciri khas perusahaan (EVP) membantu perusahaan menciptakan suatu citra sebagai pemberi kerja, karena karyawan yang berkualitas berarti diberikan kesempatan berkembang oleh pemberi kerjanya (employer). Untuk menciptakan suatu citra yang baik sebagai pemberi kerja, salah satu cara yang dilakukan adalah dengan memasarkan nilai budaya perusahaan menggunakan citra dari ketenagakerjaan yang telah dimiliki oleh perusahaan. selain dengan citra ketenagakerjaan, kualitas dari produk atau servis yang diberikan oleh perusahaan juga berhubungan dengan 
citra ketenagakerjaan yang merupakan bagian dari nilai perusahaan yang ingin dipasarkan. Kualitas dari produk perusahaan dapat menarik ketertarikan publik terhadap perusahaan tersebut sebagai employer atau tempat kerja yang dituju. Hal ini bisa menjadi salah satu alasan seorang karyawan atau calon karyawan untuk memilih perusahaan tersebut sebagai tempat bekerja.

Employer value proposition atau proposisi nilai perusahaan yang dimiliki oleh perusahaan perlu ditawarkan kepada seluruh stakeholders perusahaan baik internal maupun eksternal. Proposisi nilai perusahaan yang dimiliki haruslah unik agar tidak sama dengan yang dimiliki oleh perusahaan lainnya.

Kata 'jujur' dan 'true colors 'menjadi dua kata penting dalam pembentukan Employer Value Proposition perusahaan yang akan dipasarkan kepada publik internal dan eksternalnya. Menurut Backhauss dan Tikoo (2004: 507),

Accuracy of perceptions about the organization is particularly important because it helps to reduce perceptions of breach of the psychological contact, or worse, violations of the psychological contract on the part of new employees. Violations of the psychological contract, which can be defined as an employee's belief that the organization reneged on its obligations, have been shown to correlate positively with turnover and intentions to quit, reduced job satisfaction, reduced organizational trust, and decreased job performance.

Meskipun terdapat beberapa komponen employer branding, fondasi dari pesan-pesan employer branding adalah pengalaman, dan hubungan yang dimiliki oleh orang didalam perusahaan tersebut, yang dikomunikasikan kepada lingkungan eksternal perusahaan. Karena itu, komunikasi adalah jantung dari proses employer branding sebagai usaha yang dilakukan oleh perusahaan untuk mengkomunikasikan kepada karyawan dan calon karyawannya, apa yang membuat perusahaan tersebut menjadi perusahaan yang tepat untuk mereka (Lubecka, 2013: 7).

Employer branding adalah "image of the organization as a 'great place to work'in the minds of currentemployees and key stakeholders in the external market" (Minchinton, 2010: 37). Pernyataan ini mendukung tahapan external employer branding yang berfokus pada membangun citra perusahaan yang meningkatkan ketertarikan dari calon karyawan dan kesadaran publik akan merek perusahaan. Publik eksternal yang dimaksud dalam penelitian ini adalah kandidat pasif dan aktif, klien, konsumen, dan stakeholders kunci lainnya (Lubecka, 2013: 6).

Dalam menjalani tahap external employer branding, cara yang paling efektif untuk menjangkau banyak publik dalam waktu yang singkat adalah dengan menggunakan platform internet. Penggunaan internet (websites, media sosial, dll) memberikan kesempatan dan tantangan kepada perusahaan untuk mengembangkan dan mengkomunikasikan employer brand. Internet memberikan perusahaan akses yang besar, mudah, dan murah untuk mengembangkan employer brand. Sebagai gantinya, publik eksternal mendapatkan lebih banyak kemungkinan untuk melakukan riset dan menemukan banyak informasi mengenai image dari perusahaan yang mereka cari, serta informasi mengenai pengalaman karyawan perusahaan tersebut.

Namun, PT. Mercedes-Benz Indonesia tidak maksimal dalam melakukan aktivasi social media untuk memasarkan nilai budaya perusahaannya (Khotimah, 2019).

Pihak manajerial PT. MercedesBenz Indonesia menyatakan bahwa penggunaan sosial media sebagai 
Tasya Vicky Ryana, dkk. Proses Employer Branding PT. Mercedes-Benz Indonesia...

platform untuk memasarkan nilai budaya perusahaan dirasa tidak pas dengan perusahaan, karena sosial media perusahaan lebih banyak digunakan untuk menyebarkan informasi mengenai produk, events, serta berita-berita tentang events yang diselenggarakan oleh perusahaan. Meskipun begitu, pemasaran employer value proposition dapat dilakukan dengan melakukan aktivitas yang aktif di depan publik, salah satunya adalah CSR.

$\begin{array}{rrr}\text { CSR } & \text { didefinisikan } & \text { sebagai } \\ \text { komitmen } & \text { perusahaan } & \text { untuk }\end{array}$
meningkatkan kesejahteraan komunitas melalui praktik bisnis yang baik dan mengkontribusikan sebagian sumber daya perusahaan (Kotler, 2005). Image positif yang dibangun melalui CSR memberikan dampak kebaikan kepada perusahaan, dikarenakan CSR akan memperkuat brand image perusahaan yang pada akhirnya menjadi salah satu media promosi yang aktif atas perusahaan tersebut. Perusahaan-perusahaan yang beroperasi dengan cara membantu mensejahterakan kepentingan sosial dan melaksanakan strategi CSR, dapat meningkatkan hubungan dengan para stakeholders.

CSR kita ada beberapa program, kita aktif melaksanakan CSR karena kita sadar itu adalah cara kami untuk menciptakan kerjasama antara perusahaan dengan pihak lain, sehingga memperbesar dampak pelaksanaan promosi perusahaan juga. Berarti apa, itu usaha kami mempromosikan value perusahaan. CSR kan berkaitan dengan brand value, misi dan kesesuaian karakter perusahaan, itu penting agar kami bisa berkembang menjadi good citizen brand yang dipromosikan melalui cara social, nantinya ini akan meningkatkan citra perusahaan. (Khotimah, 2019)

Mercedes-Benz

menyadari pentingnya program CSR untuk
Indonesia pelaksanaan menciptakan hubungan dengan pihak lain atau disebut sebagai stakeholders perusahaan.

Program CSR yang dilakukan oleh PT. Mercedes-Benz Indonesia bertujuan untuk membantu mensejahterakan kehidupan warga sekitar dengan membantu meningkatkan tingkat kesejahteraan di bidang Pendidikan dan bidang lingkungan. (Prayoga, 2019)

Upaya aktif lainnya yang dapat dilakukan oleh perusahaan adalah dengan adanya komunikasi dua arah antar perusahaan dengan publiknya. Dengan mempertimbangkan peran komunikasi interpersonal, employer branding dapat menjadi sangat efektif jika adanya komunikasi antar perusahaan dengan karyawan dan publik eksternalnya yang berbentuk dialog, yang membuat partisipan komunikasi menghormati nilai dasar manusia untuk berkomunikasi secara timbal balik. Pihak manajerial PT. Mercedes-Benz Indonesia menyatakan bahwa kesempatan talkshow di acaraacara tertentu seperti Job Fair adalah upaya yang seringkali dilakukan untuk memasarkan nilai budaya perusahaan, dan untuk menarik ketertarikan publik terhadap perusahaan. PT. Mercedes-Benz Indonesia mengikuti acara seperti Job Fair atau Career Fair untuk melakukan campaign yang dapat membangun attractiveness perusahaan di pikiran publik yang dituju oleh PT. MercedesBenz Indonesia. Dinyatakan oleh pihak manajerial, PT. Mercedes-Benz Indonesia tidak bertujuan untuk menarik kandidat, tetapi untuk menanamkan awareness yang lebih tinggi tentang perusahaan. Hal ini berarti sesuai dengan fungsi external employer branding yang dijelaskan pada salah satu jurnal yang membahas tentang media dan alat yang digunakan untuk menjalankan external employer branding:

External employer branding may perform two functions. Firstly imagecreating function thataimsat increasing 
candidates' awareness of the brand, informing the job market of the company and the advantages of working in it, presenting the competitive advantage or implementing the corporate social responsibility principles. Secondly recruitment-oriented function whose most important objective is finding the most appropriate candidates and influencing them to apply for the available vacancies. (Stuss \& Herdan , 2017, p. 204).

Artinya, PT. Mercedes-Benz Indonesia menjalankan tahap external employer branding dengan fungsi yang pertama disebutkan dalam pernyataan tersebut, yaitu untuk membangun suatu citra perusahaan yang bertujuan untuk meningkatkan kesadaran tentang perusahaan sebagai suatu tempat bekerja pilihan dengan cara memberikan informasi mengenai pekerjaan dan aktivitas di perusahaan, keuntungan dari menjadi bagian dari perusahaan, kelebihan bersaing yang dimiliki perusahaan, atau menerapkan prinsip tanggung jawab sosial.

Cara lain yang mudah untuk dilakukan dan dianggap efektif untuk menyebarkan informasi perusahaan adalah dengan menggunakan websites perusahaan, telah disebutkan sebelumnya bahwa internet adalah platform yang paling mudah untuk digunakan oleh semua orang dan diakses oleh seluruh orang dari latar belakang dengan tujuan apapun, terutama untuk mencari informasi yang terbuka. Pihak manajerial PT. Mercedes-Benz Indonesia menyatakan bahwa aktivasi website perusahaan cukup aktif dilakukan dengan memberikan informasi mengenai visi misi, goals objectives perusahaan, struktur organisasi perusahaan, lowongan kerja dan magang, berita acara internal maupun eksternal, dan berbagai berita atau promo untuk produk dan servis perusahaan. Aktivasi website menjadi upaya penyebaran informasi dengan cara one-way communication karena tidak membangun timbal balik antar perusahaan dan publik.

Pemasaran nilai budaya perusahaan atau employer value proposition kepada publik eksternal pada dasarnya adalah upaya memberikan informasi tentang keunikan dan nilai berharga yang dimiliki oleh perusahaan dan menjadi ciri khas dari perusahaan tersebut yang menjadikan perusahaan tersebut berbeda dari perusahaan lainnya, kemudian itu akan menimbulkan pandangan bahwa perusahaan tersebut merupakan tempat bekerja yang baik yang memberikan janji dan alasan untuk bersama-sama berkembang dan mencapai tujuan bersama, serta menepati janji yang harus ditepati.

Tahapan terakhir dari proses employer branding yang dilakukan oleh PT. Mercedes-Benz Indonesia adalah Internal Marketing. Internal marketing dalam employer branding atau disebut dengan internal employer branding adalah suatu usaha untuk menumbuhkan perspektif karyawan terhadap suatu brand perusahaan (Hankinson, 2004). Internal employer branding memberikan pemahaman yang lebih baik tentang merek perusahaan terhadap karyawannya dengan mengkomunikasikan nilai-nilai perusahaan. Hal ini sama saja dengan mempromosikan perusahaan secara internal dengan target sasaran publiknya adalah karyawan dari perusahaan itu sendiri. Seperti apa yang disebutkan oleh Backhaus dan Tikoo,

Inside the organization, internal marketing efforts are aimed at creating a culture that reinforces desired work behaviors and supports individual quality of work life. To accomplish these goals, firms promote the existing "value" of the firms' culture or sometimes use internal marketing to make culture changes. (Backhaus \& Tikoo, 2004: 509). 
Tasya Vicky Ryana, dkk. Proses Employer Branding PT. Mercedes-Benz Indonesia...

Tahap internal marketing dari proses employer branding dimaksudkan untuk memperkuat performa kerja yang dilakukan oleh karyawan perusahaan dan mendukung kualitas dari pekerjaan tiap individu pada perusahaan tersebut. Tujuan ini dicapai dengan cara menawarkan janji-janji perusahaan dan menginternalisikan nilai-nilai yang telah dibuat dan dikembangkan oleh pihak manajerial perusahaan.

By modifying the performance management program, workgroups slowly shifted to a team-based work style. As the branding campaign gains momentum, employees buy into the new culture, aligning their behavior with that demanded by the developing norms established by the company. The more the culture supports quality of work, life, the more likely the culture will increase organizational commitment. (Backhaus \& Tikoo, 2004, p. 509)

Foreman dan Money membagi internal marketing kedalam tiga faktor: employee development, rewards, and a vision in which employees can believe (Ambler \& Barrow, 1996). Menurut pernyataan yang didapatkan oleh peneliti dari hasil wawancara dengan Niena S. Khotimah, PT. Mercedes-Benz Indonesia belum memiliki program pengembangan karyawan (employee development) yang komprehensif, ini berarti program tersebut belum dirasa menyeluruh dan belum mencakup secara luas dalam pelaksanaannya sehingga tujuan yang ingin dicapai dengan diadakannya program pengembangan karyawan tersebut belum tercapai secara maksimal. Meskipun begitu, PT. Mercedes-Benz Indonesia selalu mengadakan program pengembangan karyawan sesuai dengan kebutuhan dari setiap departemen atau business unit. Hal ini dilakukan supaya program yang dilaksanakan sesuai dengan apa yang dibutuhkan oleh setiap karyawan dalam usahanya mencapai tujuan perusahaan.

Namun, menurut pernyataan dari Rachman H. Harahap, program employee development pada PT. Mercedes-Benz Indonesia sudah dirancang dengan baik dengan membaginya ke dalam dua kategori. Sebagai anak perusahaan dari DAIMLER, PT. Mercedes-Benz Indonesia memiliki program employee development yang harus dilakukan dengan menggunakan kurikulum dari DCA (DAIMLER Corporate Academy), program ini ditujukan untuk pihak manajerial level 4 keatas. Kategori kedua, adalah program employee development yang menggunakan kurikulum yang dirancang dari pihak lokal PT. MercedesBenz Indonesia, kurikulum untuk program ini dirancang dengan cara melakukan analisis ke setiap business unit untuk menemukan kebutuhan apa yang harus dipenuhi, kemudian setelah itu barulah dirancang menjadi suatu program employee development. (Hasil wawancara dengan Rachman H. Harahap selaku HR Talent Acquisition PT. Mercedes-Benz Indonesia pada 15 April 2019)

Menurut Rosenbaum yang dikutip dari Backhaus \& Tikoo (2004: 511),

Further, the integrating role played by the internal marketing of the brand serves to develop human capital within the organization. In this respect, employer branding becomes an exercise in promoting the importance of individual career development within the organization. Without career development, individuals lose their competitive edge, and so does the firm.

Backhaus dan Tikoo menyatakan bahwa pengembangan karir individual yang diberikan oleh perusahaan kepada pihak karyawan merupakan strategi penting dari employer branding, Karena tanpa adanya program pengembangan karir karyawan atau employee 
development, setiap individu akan kehilangan rasa kompetitif dalam dirinya dan akan mempengaruhi perusahaan yang kemudian juga akan mengalami turunnya tingkat kompetitif dengan perusahaan lain yang menjadi kompetitornya.

Salah satu definisi internal marketing menyatakan bahwa, "internal marketing carries the brand "promise" made to recruits into the firm and incorporates it as part of the organizational culture" (Backhaus \& Tikoo, 2004: 503). PT. Mercedes-Benz Indonesia melakukan program-program pengembangan karir dan menjadikannya sebagai bagian dari budaya perusahaan yang kerap diikuti dan ditunggu oleh seluruh karyawan untuk mengembangkan kemampuan kerja.

Program employee development yang telah dilakukan oleh PT. MercedesBenz Indonesia diberikan kepada karyawannya dengan harapan bahwa setiap karyawan akan memberikan hasil positif kepada perusahaan dengan cara mengembangkan skill dan meningkatkan produktivitas dan performa kerja. Hasil nyata dari setiap perkembangan karyawan kerap dipantau dan dipertimbangkan oleh PT. Mercedes-Benz Indonesia untuk diberikan suatu penghargaan sebagai bukti hubungan timbal balik, dengan memberikan penghargaan kepada karyawannya yang menunjukkan kinerja yang baik sebagai bentuk rasa menghargai dari pemberi kerja kepada karyawannya. Pihak manajerial PT. Mercedes-Benz Indonesia menganggap karyawannya sebagai aset perusahaan yang menjadi roda penggerak perusahaan untuk mencapai tujuannya, karena itulah pemberian penghargaan dirasa penting. Para karyawan yang memberikan kontribusi besar dan menunjukkan performa kerja yang baik berarti membuktikan bahwa mereka adalah orang-orang yang berkualitas, dan berarti mereka sudah membantu perusahaan dalam berkembang lebih maju serta membantu perusahaan untuk mencapai tujuan utamanya (Hasil wawancara dengan Pambayun D. A. Prayoga selaku HR Marketing \& Industrial Relation PT. Mercedes-Benz Indonesia pada 15 April 2019). Hal ini didukung dengan pernyataan dari Backhaus dan Tikoo,

Satisfied employees tend to have higher performance levels and provide higher levels of customer satisfaction. Generally, positive employee attitudes toward work also positively affect customer satisfaction. Heskett call this phenomenon the service profit chain, proposing that worker capability, job satisfaction and commitment are linked to customer's perceptions of value and hence, to profits. (Backhaus \& Tikoo, 2004: 510).

Backhaus dan Tikoo menyatakan bahwa karyawan perusahaan yang merasa puas akan menunjukkan performa kerja yang lebih tinggi dan akan menstimulasi tingkat kepuasan konsumen yang lebih tinggi. Dalam PT. Mercedes-Benz Indonesia yang merupakan perusahaan yang menghasilkan produk, itu berarti performa kerja yang tinggi akan menghasilkan produk yang lebih baik dan mempengaruhi profit perusahaan yang menjadi lebih tinggi. Disebutkan juga bahwa kapabilitas dari karyawan, rasa puas dalam pekerjaan, dan komitmen akan berhubungan dengan persepi konsumen atau publik perusahaan tentang nilai-nilai perusahaan, yang kemudian juga akan berdampak pada suatu keuntungan bagi perusahaan.

Salah satu tujuan dari internal marketing dijelaskan, "the goal of internal marketing also known as internal branding, is to develop a workforce that is committed to the set of values and organizational goals established by the firm" (Backhaus \& Tikoo, 2004: 503). Hal tersebut sesuai dengan tujuan 
Tasya Vicky Ryana, dkk. Proses Employer Branding PT. Mercedes-Benz Indonesia...

PT. Mercedes-Benz Indonesia yang menggunakan tahap internal marketing sebagai cara untuk membentuk karyawannya untuk memiliki nilai-nilai dan tujuan perusahaan dalam dirinya untuk dicapai.

Dalam tahap internal marketing dari employer branding yang dilakukan PT. Mercedes-Benz Indonesia, pihak manajerial juga menanamkan suatu keyakinan/suatu hal yang dapat diyakini oleh karyawannya. PT. MercedesBenz Indonesia berharap karyawannya dapat merasa bangga menjadi bagian dari Mercedes-Benz, dan menyadari bahwa perusahaan ini telah mengayomi, membina, dan menghargai mereka sehingga akan terbentuk suatu loyalitas yang kuat dari karyawan kepada PT. Mercedes-Benz Indonesia (Khotimah, 2019).

Kegiatan internal marketing yang mengkomunikasikan employer value proposition dengan caramemberikanjanjijanji perusahaan kepada karyawannya bertujuan agar setiap karyawan dapat memahami dan turut menyampaikan setiap nilai dan ciri khas perusahaan melalui sikap dan tindakannya seharihari.

\section{SIMPULAN}

PT. Mercedes-Benz Indonesia memang memiliki nilai-nilai perusahaan atau employer value proposition yang kuat dan penerapannya sudah dapat dipertanggungjawabkan kepada karyawan dalam perusahaannya. Cascio dan Graham dalam Biswas mengatakan perusahaan harus terus mencari tahu apa yang penting bagi karyawan dan calon karyawannya, dan menjadi keinginan mereka (Biswas, Allard, Pousette, \& Harenstam, 2017: 32). Untuk melakukan upaya itu, manajerial dan HR melakukan tanggung jawabnya dengan melakukan survei anonim, menggunakan kotak saran untuk karyawan yang telah dimiliki perusahaan, dan exit interview dengan karyawan yang akan meninggalkan perusahaan. Wilden (2010) dalam penelitiannya juga menyarankan bahwa untuk meningkatkan sinyal merek (berupa nilai-nilai perusahaan atau evp) kepada karyawan dan calon karyawan, bergantung pada konsistensi, kejelasan, dan kredibilitas, terkait dengan employer brand. Hal ini berarti, perusahaan dapat mengembangkan nilai merek perusahaan sebagai pemberi kerja (employer brand) dengan terus menunjukkan transparansi dan kejujuran perusahaan tentang apa yang dimiliki dan diterapkan dalam perusahaan.

PT. Mercedes-Benz Indonesia menggunakan beberapa cara dalam melakukan tahap external employer branding, namun seluruh aktivitas yang dilakukan hanya menargetkan calon karyawan dan publik umum. Chignell (2018) menyarankan cara untuk meningkatkan efektivitas upaya pemasaran eksternal dari employer branding, seperti berusaha untuk mengenalkan budaya perusahaan kepada publiknya, perusahaan juga perlu mengenalkan kerja keras yang dilakukan dan hasilnya.

Sosial media adalah media yang efektif untuk digunakan sebagai tempat berbagi cerita. Sebuah cerita mengenai seseorang atau karyawan menjalankan pekerjaan dengan baik di lingkungan yang menyenangkan akan membangun sebuah pesan yang kuat untuk publik yang mempertimbangkan untuk bergabung dalam perusahaan. Mennyampaikan cerita tentang pengalaman karyawan melalui sosial media adalah cara efektif yang harus dilakukan oleh perusahaan untuk mengenalkan nilai perusahaan sebagai pemberi kerja. Karena itu, tahap external marketing dapat dimaksimalkan dengan lebih mengaktifkan sosial media sebagai platform yang digunakan untuk memasarkan EVP. Penggunaan sosial 
media lebih baik digunakan lebih aktif dalam menyebarkan informasi mengenai keunikan dan kelebihan perusahaan sebagai pemberi kerja dan tempat bekerja karena sosial media adalah media yang efektif untuk menjangkau banyak publik.

Tahap terakhir, kegiatan internal marketing dari employer branding merupakan kegiatan yang dilakukan dari dalam kedalam namun akan memberikan dampak keluar, maka sasaran yang dituju adalah karyawan yang merupakan publik internal perusahaan.

The corporate communications department encouraged internal branding by created corporate attributes which also an effort to strengthen its corporate identity, it was also an effort to strengthen corporate identity to internal stakeholders. (Lestari, Dimyati, \& Shihab, 2017: 47)

Usaha internal marketing dari employer branding juga merupakan upaya untuk menguatkan identitas perusahaan kepada pihak internal. Ferhatovic dan Tabea (2016, p. 50) menyarankan perusahaan besar untuk membangun hubungan emosional yang baik antar karyawan dan perusahaan secara lebih maksimal, dengan memberikan usaha yang lebih besar dalam meningkatkan komunikasi dan keterkaitan antar departemen. Usaha ini dapat dilakukan dengan mengadakan lebih banyak acara sosial dimana karyawan dari departemen yang berbeda dapat berinteraksi dengan intensitas yang lebih tinggi. Untuk membuat karyawan merasa koneksi yang lebih erat dengan perusahaan, Ferhatovic dan Tabea juga menyarankan perusahaan untuk membentuk platform dimana seluruh pihak dalam perusahaan dalam berkolaborasi untuk membentuk suatu solusi bisnis yang baru.

\section{DAFTAR PUSTAKA}

Ambler, T., \& Barrow, S. (1996). The
Employer Brand. The Journal of Brand Management, 185-206.

Backhaus, K., \& Tikoo, S. (2004). Conceptualizing and Researching Employer Branding. Career Development International, 501-517.

Biswas, U., Allard, K., Pousette, A., \& Harenstam, A. (2017). Understanding Attractive Work in a Globalized World. India and Sweden: Springer.

Chignell, B. (2018, November 29). 11 simple steps to improve your employer branding. Retrieved from CIPHR ALL ABOUT PEOPLE: https://www. ciphr.com/advice/11-ways-improveemployer-brand/

Ferhatovic, A., \& Simon, T. (2016). The Process of Adapting the Employer Brand to Attract the Right Employees - A Case Study of How SEB Uses Employer Branding to Go Digitial. Uppsala, Sweden: Uppsala University.

Hankinson, P. (2004). The Internal Brand in Leading UK Charities. Journal of Product \& Brand Management, 84-93.

Kotler, Philip dan Nancy Lee. (2005). Corporate Social Responsibility; Doing the Most

Good you're your Company and Your Cause. NewJersey; John Wiley\&Sons, Inc.

Lestari, Dimyati, \& Shihab. (2017). Strategic Communications and Corporate Branding:

A Study of Jebsen \& Jessen Indonesia Group. MediaTor, 37-52.

Lubecka, A. (2013). Employer branding - a dialogistic communication tool of a competitive employer. Journal of Intercultural Management, 5-16.

Stuss, M., \& Herdan , A. (2017). External Employer Branding Tools Used for Attracting Graduates by Energy Companies Listed at Warsaw Stock Exchange. 8th Economics \& Finance Conference (pp. 200-213). London: ResearchGate.

Wilden, R., Gudergan, S., \& Lings, I. (2010). Employer branding: strategic implications for staff recruitment. Journal of Marketing Management, 56-73. 